\title{
Socioeconomic status and outcomes after sport-related concussion: a preliminary investigation
}

\author{
Scott L. Zuckerman, MD, ${ }^{1,2}$ Brian Holt Zalneraitis, BS, ${ }^{1}$ Douglas J. Totten, BA, ${ }^{1}$ Kolin E. Rubel, BS, ${ }^{3}$ \\ Andrew W. Kuhn, BA, ${ }^{1}$ Aaron M. Yengo-Kahn, MD, ${ }^{1,2}$ Christopher M. Bonfield, MD, ${ }^{1,2}$ \\ Allen K. Sills, MD, ${ }^{1,2}$ and Gary S. Solomon, $\mathrm{PhD}^{1,2}$
}

${ }^{1}$ Vanderbilt Sports Concussion Center and ${ }^{2}$ Department of Neurological Surgery, Vanderbilt University School of Medicine, Nashville, Tennessee; and ${ }^{3}$ University of Indiana School of Medicine, Indianapolis, Indiana

\begin{abstract}
OBJECTIVE. A significant proportion of patients experience long-term symptoms after sport-related concussion (SRC), and several factors have been associated with this protracted recovery. Limited data exist on the role of socioeconomic status (SES) on SRC outcomes. The objective in this study was to conduct a preliminary investigation to determine the effect of SES on outcomes after SRC in student-athletes treated at a regional sports concussion center.

METHODS. A retrospective cohort study of 282 middle school, high school, and collegiate student-athletes was conducted. An attempt was made to contact all patients seen at a comprehensive SRC center between January 2012 and May 2015 for in-depth interviews. Subsequent demographic data were collected. The SES was defined as follows: cost of living percentile, median income percentile, percentage of college graduates, percentage of homeowners, county type, and insurance status. Outcomes after SRC were defined as follows: days of symptom duration, days of missed school, and days of missed practice. Statistically controlled covariates included sex, race, age, body mass index, concussion history, neuropsychiatric history, and type of sport.
\end{abstract}

RESULTS. A total of 282 student-athletes consented and were studied. The median age was 15.8 years (range 11.622.2 years) and $61.4 \%$ of student-athletes were male. A previous concussion was incurred by $34.0 \%$ of student-athletes. Football was the most common sport (32.3\%), followed by soccer (16.3\%), and basketball (15.6\%). The median symptom duration was 21 days (range 1-365 days); the median missed school days was 2 (range 0-90 days); and median for days of missed practice was 10 (range 0-150 days). After multivariate Cox regression analysis, no relationship between any of the 6 SES variables and symptom duration or missed practice was seen. However, individuals with private insurance had more missed days of school than those with public insurance (hazard ratio $0.46,95 \% \mathrm{Cl} 0.26-0.83, p=0.009$ ).

CONCLUSIONS. In a preliminary study of middle school, high school, and collegiate student-athletes, SES had no impact on the outcomes of symptom duration and missed practice. However, for individuals with private insurance, the return to school was slower than for those with public insurance. This pilot study reveals the complex relationship between SES and SRC recovery, which demands further study with more accurate and validated assessments of SES.

https://thejns.org/doi/abs/10.3171/2017.1.PEDS16611

KEY WORDS socioeconomic status; sports-related concussion; traumatic brain injury; football; basketball; soccer; athletics; postconcussion syndrome; trauma

$\mathrm{S}$ PORT-related concussion (SRC) has surfaced as a public health concern in recent years. Approximately $1.6-3.8$ million SRCs are reported annually, ${ }^{10}$ with an estimated 136,000 SRCs occurring in high school athletics alone. ${ }^{5}$ Additionally, $10 \%-15 \%$ of patients develop persistent symptoms following SRC. ${ }^{7,19,33}$ Given the po- tential for long-term disability, it is important to determine factors that may predict a protracted recovery.

Currently, no diagnostic test exists to determine severity of injury after SRC; often the injury severity is assessed through symptom duration or time away from school or sport. ${ }^{29}$ Several risk factors have been associated with re-

ABBREVIATIONS BMI = body mass index; EMR = electronic medical record; $\mathrm{HR}=$ hazard ratio; $I \mathrm{QR}=$ interquartile range; $\mathrm{SES}=$ socioeconomic status; $\mathrm{SRC}=\mathrm{sport}-$ related concussion; TBI, $\mathrm{mTBI}=$ traumatic brain injury, mild TBI; VSCC = Vanderbilt Sports Concussion Center.

SUBMITTED November 4, 2016. ACCEPTED January 24, 2017.

INCLUDE WHEN CITING Published online March 24, 2017; DOI: 10.3171/2017.1.PEDS16611. 
covery time, including severity of symptoms, history of concussion, personal and family history of preinjury migraines and mood disorders, and sex..$^{14,17,19}$ Other factors, such as socioeconomic status (SES), have yet to be investigated.

Socioeconomic status has been studied mostly in moderate and severe traumatic brain injury (TBI), in which lower SES has been generally associated with worse social outcomes, ${ }^{6,32}$ although the literature is mixed. ${ }^{24}$ In one of the few studies specific to mild TBI (mTBI), lower SES significantly predicted a poor cognitive outcome at 3 months postinjury. ${ }^{23}$ In relation to sports injuries, our search yielded no specific studies relating SES to SRC outcomes.

Given that SES is a novel factor in the study of SRC with limited to no data, the current objective was to conduct a pilot study examining the impact of SES on recovery after SRC among a cohort of middle school, high school, and collegiate student-athletes. Evaluating novel factors related to SES and SRC recovery may elucidate important trends and generate new hypotheses that demand rigorous scientific study.

\section{Methods}

A retrospective cohort study was conducted at a regional sports concussion center. The Vanderbilt Sports Concussion Center (VSCC) outcomes registry database was launched in 2013 and data-collection efforts remain ongoing. Student-athletes across middle Tennessee and the surrounding states of Kentucky, Georgia, and Alabama who presented to the VSCC for treatment were included in the database. The current study was approved by our institutional review board.

\section{Inclusion and Exclusion Criteria}

A total of 699 patients who suffered SRC were seen at the VSCC between January 2012 and May 2015 by 5 interdisciplinary providers from adult and pediatric neurosurgery, neuropsychology, and sports medicine. As noted in Fig. 1, of the 699 patients with SRC, complete data were collected for 295 patients $(42 \%)$. The population studied included middle school, high school, and collegiate student-athletes participating in team or individual sports. Student-athletes were excluded if they were not playing at these levels of competition or if they had a history of brain surgery, seizures, or meningitis. After exclusionary criteria were applied, our final cohort included 282 student-athletes. All concussions were diagnosed in accordance with the definition provided by the international Concussion in Sport Group (CISG) guidelines..$^{15}$ Diagnoses were made by certified athletic trainers or team physicians based on the following on-field or sideline signs or symptoms: 1) lethargy, fogginess, headache, dizziness,

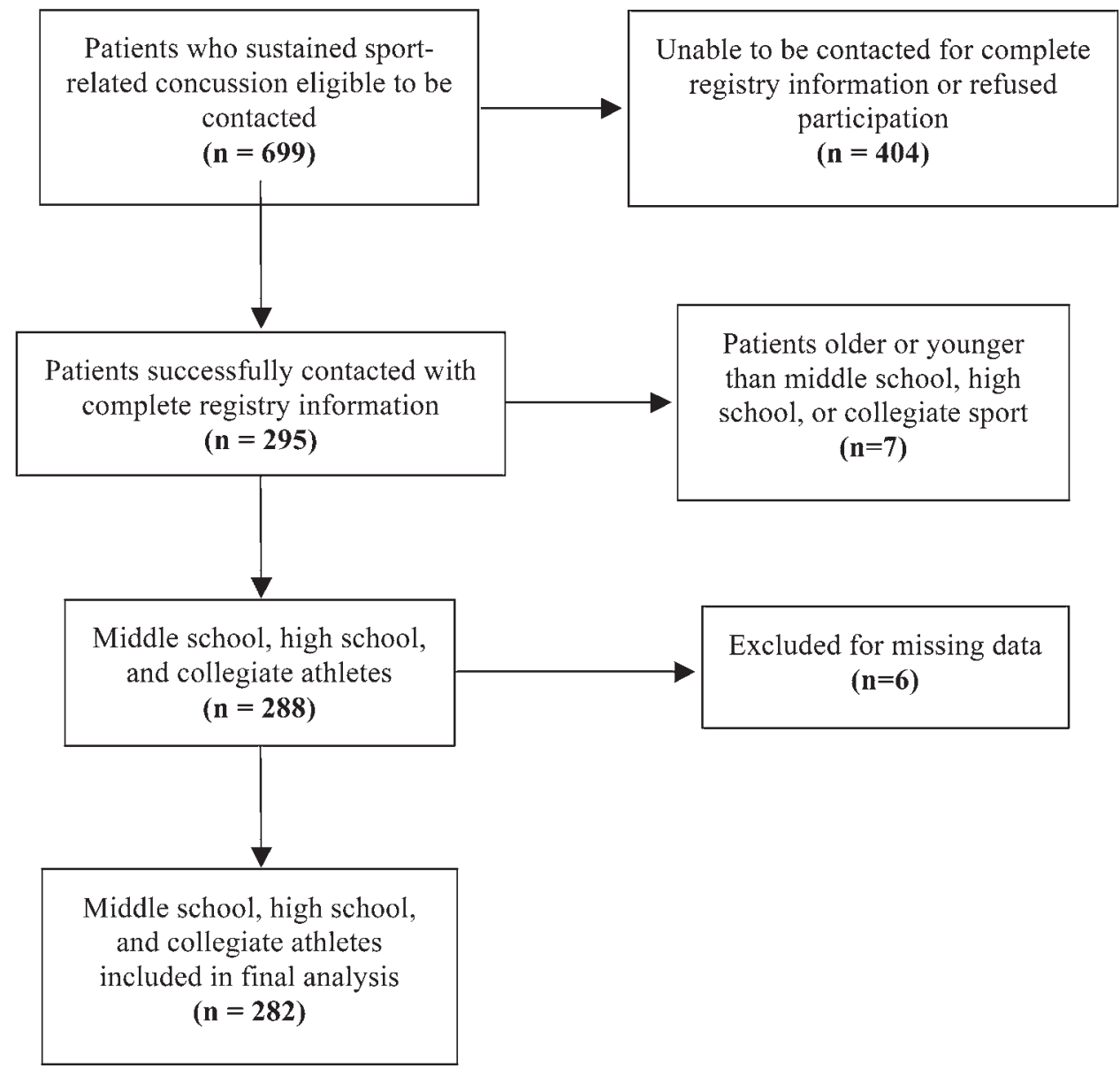

FIG. 1. Flow diagram of final cohort. 
nausea, visual problems, photophobia, or phonophobia; 2) alteration in mental status; 3 ) loss of consciousness; or 4) amnesia. Grading systems of concussion severity were not used, based on the aforementioned Concussion in Sport Group guidelines. ${ }^{15}$

\section{Data Collection}

In-depth phone interviews were completed to collect all SRC information. Each interview was standardized and similarly structured. All patients and families were contacted a minimum of 3 months after the injury to allow for symptom resolution. In addition to interviewing the concussed student-athlete, a parent or guardian was also interviewed for each patient younger than 18 years or when available. Collateral information was obtained because most patients were adolescents or teenagers (i.e., in middle school or high school) and not all SRC information may have been readily known due to loss of consciousness or amnesia surrounding the event. Multiple contacts were often required per patient to obtain complete data. If the patient was still symptomatic during the interview, additional contacts were made until symptoms had resolved or 1 year had passed postinjury.

Several data points were collected for each patient, including demographic information, medical history, family history, acute injury characteristics, and symptom duration. The institutional electronic medical records (EMRs) were used to cross-validate already gathered data. Any discrepancies between patient interviews and the EMRs were resolved with additional patient contacts. All data were maintained in a de-identified database.

For the current study, the extracted demographic, family, and past medical information included the following: sex, race, age, body mass index (BMI), concussion history, and neuropsychiatric history, including attention deficit disorder and/or learning disorders, depression or anxiety, psychiatric disorders, or any positive history of such findings in any parent, sibling, or child. The SRC event data included mechanisms of injury (described below). Clinical outcome data included duration of symptoms and achievement of asymptomatic status.

\section{Socioeconomic Status}

The literature on SES determination is vast and be- yond the scope of this study. Based on the TBI and sports medicine literature, we chose to study factors including education, employment, income, and general family environment. ${ }^{4,11,12,20,22,30,31}$ Although these specific factors may not represent an ideal definition of SES, these variables and information were available in all patients. Unfortunately, the socioeconomic variables included in this study were not obtained directly from the patients and families themselves due to the original registry design. Thus, surrogate measures had to be used. The SES was defined a priori as 6 different variables: cost of living percentile, ${ }^{11}$ median income percentile, ${ }^{1}$ percentage of college graduates, ${ }^{1}$ home ownership, ${ }^{4}$ county setting, ${ }^{8}$ and insurance status. $^{12,22}$ All variables except insurance status were based on the patient's zip code at the time of injury. Insurance status was gathered from the EMR. Continuous percentage variables were transformed into categorical variables for ease of data analysis. Description of each variable is presented in Table 1.

\section{Outcomes}

Three main SRC outcomes of interest were assessed: symptom duration, missed school, and missed practice. Each outcome variable was measured in days as a continuous variable. Symptom duration was defined as the student-athlete experiencing self-reported symptoms attributable to the initial injury. Missed school was defined as the number of school days missed. If a student-athlete suffered an SRC during the summer months while out of school, missed school was not included. Missed practice was counted as the number of team practices missed that was attributable to the initial injury. In our practice, athletes are always returned to school prior to return to sport.

\section{Statistical Analyses}

For all descriptive analyses, continuous variables were reported as a median with corresponding interquartile range (IQR) and overall range, and binary count variables with number (\%). Five of the 6 exposures of interest were categorical, with insurance status coded as binary. All 3 outcomes of interest (symptom resolution, return to school, and return to practice) were continuous and measured in days. The study period for each patient was 365 days. Patients who did not achieve symptom resolution by

TABLE 1. Definitions of variables used to test SES

\begin{tabular}{|c|c|c|}
\hline Exposure & Definition & Source \\
\hline 1. Cost of living & $\begin{array}{l}\text { Average cost of basic living expenses for each given area to assess both } \\
\text { participants' wealth/income \& geographic setting. }\end{array}$ & Marcin et al., 2003 \\
\hline 2. Median income & $\begin{array}{l}\text { Income level earned by any given household, w/ half of the homes in the } \\
\text { area earning more \& half earning less. }\end{array}$ & Adler \& Newman, 2002 \\
\hline $\begin{array}{l}\text { 3. Percent college } \\
\text { graduates }\end{array}$ & $\begin{array}{l}\text { Percentage of the population in the area that graduated from college, for use } \\
\text { in determining education attainment. }\end{array}$ & Adler \& Newman, 2002 \\
\hline 4. Home ownership & $\begin{array}{l}\text { Percentage of homes in the area that are owned by their occupants, for use } \\
\text { in determining wealth/income. }\end{array}$ & Collins et al., 2016 \\
\hline 5. County setting & Assessment of the type of geographic setting based on city size. & Ingram \& Franco, 2014 \\
\hline 6. Insurance status & $\begin{array}{l}\text { Determination of study participants' insurance status as either private or } \\
\text { public (government provided). }\end{array}$ & $\begin{array}{l}\text { Max et al., 2005; Penson et } \\
\quad \text { al., } 2001\end{array}$ \\
\hline
\end{tabular}


365 days were censored by design. These censored patients were included in the analysis without achieving the outcome.

In addition to Kaplan-Meier failure plots, univariate and multivariable Cox regression models were conducted to estimate the relationship between each of the 6 SES exposures to the 3 outcomes. Several modifying factors were included as covariates in each model: age, sex, race, BMI, concussion history, psychiatric history, and sport. The hazard function was defined as the instantaneous risk of achieving the event of interest at time (t) in the subset who still had symptoms. Indicator variables were used for each exposure category. For each Cox regression model, all hazard ratios (HRs) with 95\% CIs not containing 1.0 were considered statistically significant. All statistical analysis was performed in STATA version 14 (StataCorp LP).

\section{Results}

\section{Patient Demographic Data}

The majority of student-athletes were male (61.4\%), and football was the most represented sport (32.3\%). The median BMI was 22.1, ranging from 14.7 to 45.2. Approximately one-third (34.0\%) of the study group had a history of at least 1 SRC prior to the current event. Migraines were the most prevalent comorbidity (18.4\%), and $35.6 \%$ of student-athletes had a positive family psychiatric history. The majority of student-athletes competed at the high school level (69.5\%), followed by middle school (20.2\%) and collegiate $(10.3 \%)$ athletes. All demographic data, each of the 6 SES domains, and the 3 outcomes are summarized in Table 2.

\section{Regression Analysis}

All univariate and multivariable Cox regression models are seen in Tables 3-5. Kaplan-Meier failure plots of symptom duration, missed school, and missed practicemeasured in days - are seen in Figs. 2-4. For the outcomes of symptom duration and missed practice, none of the Cox regression models revealed a significant trend on univariate or multivariable testing (Tables 3 and 5). However, for the outcome of missed school, insurance status was found to be significant. The return to school for those with private insurance was more likely to be slower than for those with public insurance, both on univariate (HR $0.52,95 \%$ CI $0.31-0.87 ; \mathrm{p}=0.013$ ) and multivariable testing (HR 0.46, 95\% CI 0.26-0.83; $\mathrm{p}=0.009$ ) (Table 4). This trend is seen graphically in Fig. 5. After log-rank test, this trend was confirmed; student-athletes with private insurance missed significantly more school than student-athletes with public insurance $\left(\chi^{2}=7.63, p=0.0057\right)$. Of those with public insurance, the mean and median of missed school days were both 2.0, ranging from 0 to 8 days, with an SD of 2.1. Of those with private insurance, the mean and median missed school days was 5.2 and 2.0, respectively, ranging from 0 to 90 days, with an SD of 10.6.

\section{Discussion}

In the evaluation of student-athletes after SRC, several factors that modify recovery have been postulated, yet
TABLE 2. Characteristics of the 282 student-athletes

\begin{tabular}{|c|c|}
\hline Characteristic & Value \\
\hline \multicolumn{2}{|l|}{ Demographic data } \\
\hline Male & $173(61.4)$ \\
\hline \multicolumn{2}{|l|}{ Race } \\
\hline White & $241(85.5)$ \\
\hline Non-white & $41(14.5)$ \\
\hline \multicolumn{2}{|l|}{ Age in yrs } \\
\hline Median (IQR) & $15.8(14.3-18.3)$ \\
\hline Min-max & $11.6-22.2$ \\
\hline \multicolumn{2}{|l|}{$\mathrm{BMI}$} \\
\hline Median (IQR) & $22.1(20.4-25.1)$ \\
\hline Min-max & $14.7-45.2$ \\
\hline Previous concussion & $96(34.0)$ \\
\hline \multicolumn{2}{|l|}{ Neuropsychiatric history } \\
\hline LD/ADHD & $30(10.6)$ \\
\hline Depression/anxiety & $11(3.9)$ \\
\hline Migraine & $52(18.4)$ \\
\hline Illicit substance abuse & $8(2.8)$ \\
\hline Family psychiatric & $100(35.5)$ \\
\hline Family migraine & $56(19.9)$ \\
\hline \multicolumn{2}{|l|}{ Competition level } \\
\hline Middle school & $57(20.2)$ \\
\hline High school & $196(69.5)$ \\
\hline Collegiate & $29(10.3)$ \\
\hline \multicolumn{2}{|l|}{ Sport } \\
\hline Football & $91(32.3)$ \\
\hline Soccer & $46(16.3)$ \\
\hline Basketball & $44(15.6)$ \\
\hline Baseball/softball & $17(6)$ \\
\hline Lacrosse & $18(6.4)$ \\
\hline Cheerleading & $15(5.3)$ \\
\hline Volleyball & $10(3.6)$ \\
\hline Rugby & $4(1.4)$ \\
\hline Wrestling & $12(4.3)$ \\
\hline Other & $25(8.9)$ \\
\hline \multicolumn{2}{|l|}{ Exposure } \\
\hline \multicolumn{2}{|l|}{ Cost of living percentile } \\
\hline $0-50$ & $72(25.5)$ \\
\hline $51-70$ & $103(36.5)$ \\
\hline$>70$ & $107(37.9)$ \\
\hline \multicolumn{2}{|l|}{ Median income percentile } \\
\hline $0-59$ & $77(27.3)$ \\
\hline $60-79$ & $114(40.4)$ \\
\hline$\geq 80$ & $91(32.3)$ \\
\hline \multicolumn{2}{|l|}{ College graduates } \\
\hline $0 \%-20 \%$ & $100(35.5)$ \\
\hline $21 \%-47 \%$ & $100(35.5)$ \\
\hline$\geq 48 \%$ & $82(29.1)$ \\
\hline
\end{tabular}

CONTINUED ON NEXT PAGE » 
» CONTINUED FROM PREVIOUS PAGE

TABLE 2. Characteristics of the 282 student-athletes

\begin{tabular}{|c|c|}
\hline Characteristic & Value \\
\hline \multicolumn{2}{|l|}{ Exposure (continued) } \\
\hline \multicolumn{2}{|l|}{ Home ownership } \\
\hline $0 \%-71 \%$ & $98(34.8)$ \\
\hline $71.1 \%-80 \%$ & $63(22.3)$ \\
\hline$>80 \%$ & $121(42.9)$ \\
\hline \multicolumn{2}{|l|}{ County setting } \\
\hline Large central metro & $85(30.1)$ \\
\hline Large fringe metro & $164(58.2)$ \\
\hline Small/medium metro & $33(11.7)$ \\
\hline \multicolumn{2}{|l|}{ Insurance } \\
\hline Private & $255(90.4)$ \\
\hline Public & $27(9.6)$ \\
\hline \multicolumn{2}{|l|}{ Outcomes } \\
\hline \multicolumn{2}{|l|}{ Symptom duration, days } \\
\hline Median (IQR) & $21(11-61)$ \\
\hline Min-max & $1-365$ \\
\hline \multicolumn{2}{|l|}{ Missed school, days } \\
\hline Median (IQR) & $2(0-5)$ \\
\hline Min-max & $0-90$ \\
\hline \multicolumn{2}{|l|}{ Missed practice, days } \\
\hline Median (IQR) & $10(4.5-20)$ \\
\hline Min-max & $0-150$ \\
\hline
\end{tabular}

$\mathrm{ADHD}=$ attention deficit/hyperactivity disorder; $\mathrm{LD}=$ learning disorder; $\max =$ maximum; $\min =$ minimum.

Unless otherwise specified, the values represent the number of patients (\%).

little has been studied about the importance of SES. In our preliminary study from the VSCC, several different surrogates of convenience for SES were selected to evaluate their impact on SRC outcomes. No SES surrogates were found to correlate with duration of symptoms and return to sport. However, individuals with private insurance took longer to return to school than those with public insurance. Results from our pilot investigation may generate new hypotheses for future investigations.

Recovery after SRC is a complex process. When communities of parents, teachers, and coaches are heavily involved in the rehabilitation of a student-athlete, community-level intervention may potentially improve outcomes. It has been well studied that after moderate and severe TBI, children from lower-SES families develop more behavioral and social problems, with lower achievement than their advantaged counterparts. ${ }^{6,13,24-26}$ SES has previously been defined in many ways. One study used a Socioeconomic Composite Index composed of annual family income, social resources, and maternal education, ${ }^{25}$ similar to our study. However, most of this prior research was performed in young children $(<10$ years old) who sustained a severe TBI. It is difficult to extrapolate these findings to a concussion population due to different injury severities, multiorgan system involvement, and varying stages of brain development.

With respect to more mild brain injuries, Rabinowitz et al. ${ }^{23}$ evaluated predictors of persistent dysfunction in adolescents and young adults with mTBI compared to orthopedic and uninjured controls. Interestingly, the authors found that SES (defined by the aforementioned Socioeconomic Composite Index) correlated with 3-month cognitive recovery but did not predict symptom endorsement. The authors postulated that lower SES was a marker of decreased cognitive reserve, and those with less cognitive reserve were more susceptible to cognitive declines. In a similar evaluation, Olsson et al. ${ }^{21}$ evaluated 150 children and their parents after mTBI and found that child symptom burden at 6 and 18 months was predicted by preinjury parent distress, which may be intertwined with SES. Conversely, McNally and colleagues ${ }^{16}$ evaluated 186 adolescents with mTBI compared to 99 orthopedic controls and found no relationship between life stressors or social resources and child symptom duration, similar to our findings. Although useful, these studies were not conducted in a sports population. The outcomes of interest after general mTBI (education, achievement, behavioral problems) are different from those after sport-specific injury (return to play, return to learn, symptom resolution, neurocognitive test scores, postural stability). Counseling from coaches and athletic trainers, a desire to return to sport, and sportspecific outcomes are subtle yet important factors that reinforce the uniqueness of sports concussions.

No prior studies were found in the literature that directly assessed the impact of SES on outcomes in an exclusively SRC population. In our pilot investigation, 6 rudimentary SES domains spanning education and income levels had no correlation with symptom duration and athletic participation. However, a relationship between insurance status and missed school was discovered, in which those with private insurance missed more school than those with public insurance.

It is possible that student-athletes with private health insurance were more likely to receive medical care by a concussion specialist who recommended cognitive rest, which led to a longer time away from school. One survey-based study of high school athletic trainers found that cognitive rest was most commonly recommended, ${ }^{9}$ but a similar study of emergency room discharge instructions found cognitive rest was prescribed in only $4 \%$ of cases. ${ }^{28}$ A recent randomized controlled trial of 88 pediatric concussions seen in the emergency room (not exclusively due to sports) compared strict rest for 5 days versus usual care, consisting of 1-2 days of rest with a stepwise return to activity. Despite the intervention group reporting lower school attendance, no significant difference in neurocognitive and balance outcomes was seen, except that the group prescribed rest endorsed more postconcussive symptoms and slower symptom resolution time. ${ }^{27}$

A second explanation of our findings is that those with public insurance, representing a lower socioeconomic group, returned to school as dictated by their symptoms, teachers, or parents, without seeing a health care professional. This return to school may have been appropriate, or may have been premature-the current study cannot determine either case. This latter example of students returning to school prematurely may be more common. Researchers from a family and sports medicine practice in 
TABLE 3. SES as a predictor of symptom duration

\begin{tabular}{|c|c|c|c|c|}
\hline \multirow[b]{2}{*}{ SES Exposure } & \multicolumn{2}{|c|}{ Univariate } & \multicolumn{2}{|c|}{ Multivariable } \\
\hline & $\mathrm{HR}(95 \% \mathrm{Cl})$ & $p$ Value & $\mathrm{HR}(95 \% \mathrm{Cl})$ & $p$ Value \\
\hline \multicolumn{5}{|l|}{ Cost of living percentile } \\
\hline $0-50$ & Reference & Reference & Reference & Reference \\
\hline $51-70$ & $0.98(0.70-1.30)$ & 0.779 & $1.09(0.77-1.52)$ & 0.636 \\
\hline$>70$ & $1.03(0.76-1.40)$ & 0.828 & $1.02(0.73-1.43)$ & 0.891 \\
\hline \multicolumn{5}{|l|}{ Median income percentile } \\
\hline $0-59$ & Reference & Reference & Reference & Reference \\
\hline $60-79$ & $0.99(0.74-1.33)$ & 0.959 & $0.94(0.68-1.29)$ & 0.693 \\
\hline$\geq 80$ & $1.15(0.85-1.57)$ & 0.368 & $1.06(0.76-.47)$ & 0.744 \\
\hline \multicolumn{5}{|l|}{ College graduates } \\
\hline $0 \%-20 \%$ & Reference & Reference & Reference & Reference \\
\hline $21 \%-47 \%$ & $1.02(0.77-1.36)$ & 0.865 & $1.00(0.73-1.35)$ & 0.975 \\
\hline$\geq 48 \%$ & $1.11(0.83-1.50)$ & 0.478 & $1.09(0.79-1.50)$ & 0.601 \\
\hline \multicolumn{5}{|l|}{ Home ownership } \\
\hline $0 \%-71 \%$ & Reference & Reference & Reference & Reference \\
\hline $71.1 \%-80 \%$ & $1.02(0.74-1.41)$ & 0.889 & $0.92(0.64-1.32)$ & 0.651 \\
\hline$>80 \%$ & $1.02(0.77-1.33)$ & 0.911 & $0.98(0.73-1.32)$ & 0.901 \\
\hline \multicolumn{5}{|l|}{ County setting } \\
\hline Large central metro & Reference & Reference & Reference & Reference \\
\hline Large fringe metro & $0.93(0.71-1.21)$ & 0.584 & $0.89(0.66-1.20)$ & 0.457 \\
\hline Small/medium metro & $1.04(0.69-1.55)$ & 0.865 & $0.85(0.55-1.33)$ & 0.486 \\
\hline Insurance status & $1.08(0.72-1.62)$ & 0.704 & $0.87(0.54-1.42)$ & 0.583 \\
\hline
\end{tabular}

TABLE 4. SES as a predictor of missed school

\begin{tabular}{|c|c|c|c|c|}
\hline \multirow[b]{2}{*}{ SES Exposure } & \multicolumn{2}{|c|}{ Univariate } & \multicolumn{2}{|c|}{ Multivariable } \\
\hline & $\mathrm{HR}(95 \% \mathrm{Cl})$ & $p$ Value & $\mathrm{HR}(95 \% \mathrm{Cl})$ & p Value \\
\hline \multicolumn{5}{|l|}{ Cost of living percentile } \\
\hline $0-50$ & Reference & Reference & Reference & Reference \\
\hline $51-70$ & $0.74(0.52-1.08)$ & 0.116 & $0.78(0.53-1.16)$ & 0.222 \\
\hline$>70$ & $0.80(0.55-1.16)$ & 0.236 & $0.77(0.51-1.16)$ & 0.213 \\
\hline \multicolumn{5}{|l|}{ Median income percentile } \\
\hline $0-59$ & Reference & Reference & Reference & Reference \\
\hline $60-79$ & $0.82(0.57-1.17)$ & 0.268 & $0.83(0.57-1.22)$ & 0.341 \\
\hline$\geq 80$ & $0.91(0.62-1.32)$ & 0.608 & $0.88(0.58-1.35)$ & 0.565 \\
\hline \multicolumn{5}{|l|}{ College graduates } \\
\hline $0 \%-20 \%$ & Reference & Reference & Reference & Reference \\
\hline $21 \%-47 \%$ & $0.79(0.56-.11)$ & 0.176 & $0.77(0.53-1.11)$ & 0.160 \\
\hline$\geq 48 \%$ & $0.86(0.59-1.25)$ & 0.431 & $0.85(0.57-1.29)$ & 0.449 \\
\hline \multicolumn{5}{|l|}{ Home ownership } \\
\hline $0 \%-71 \%$ & Reference & Reference & Reference & Reference \\
\hline $71.1 \%-80 \%$ & $1.30(0.89-1.89)$ & 0.179 & $1.27(0.84-1.94)$ & 0.258 \\
\hline$>80 \%$ & $1.14(0.82-1.60)$ & 0.430 & $1.15(0.80-1.65)$ & 0.442 \\
\hline \multicolumn{5}{|l|}{ County setting } \\
\hline Large central metro & Reference & Reference & Reference & Reference \\
\hline Large fringe metro & $1.05(0.76-1.45)$ & 0.745 & $1.02(0.70-1.50)$ & 0.903 \\
\hline Small/medium metro & $1.42(0.89-2.29)$ & 0.144 & $1.50(0.89-2.53)$ & 0.132 \\
\hline Insurance status & $0.52(0.31-0.87)$ & $0.013^{*}$ & $0.46(0.26-0.83)$ & $0.009^{*}$ \\
\hline
\end{tabular}

* Statistically significant $(p<0.05)$. 
TABLE 5. SES as a predictor of missed practice

\begin{tabular}{|c|c|c|c|c|}
\hline \multirow[b]{2}{*}{ SES Exposure } & \multicolumn{2}{|c|}{ Univariate } & \multicolumn{2}{|c|}{ Multivariable } \\
\hline & $\mathrm{HR}(95 \% \mathrm{Cl})$ & $p$ Value & $\operatorname{HR}(95 \% \mathrm{Cl})$ & $p$ Value \\
\hline \multicolumn{5}{|l|}{ Cost of living percentile } \\
\hline $0-50$ & Reference & Reference & Reference & Reference \\
\hline $51-70$ & $0.89(0.64-1.22)$ & 0.464 & $0.95(0.66-1.36)$ & 0.782 \\
\hline$>70$ & $1.04(0.76-1.42)$ & 0.812 & $1.00(0.69-1.43)$ & 0.993 \\
\hline \multicolumn{5}{|l|}{ Median income percentile } \\
\hline $0-59$ & Reference & Reference & Reference & Reference \\
\hline $60-79$ & $0.82(0.60-1.12)$ & 0.206 & $0.83(0.59-1.16)$ & 0.263 \\
\hline$\geq 80$ & $1.11(0.80-1.54)$ & 0.534 & $1.02(0.71-1.47)$ & 0.914 \\
\hline \multicolumn{5}{|l|}{ College graduates } \\
\hline $0 \%-20 \%$ & Reference & Reference & Reference & Reference \\
\hline $21 \%-47 \%$ & $1.01(0.75-1.36)$ & 0.938 & $0.94(0.68-1.30)$ & 0.707 \\
\hline$\geq 48 \%$ & $1.20(0.87-1.64)$ & 0.266 & $1.08(0.77-1.52)$ & 0.646 \\
\hline \multicolumn{5}{|l|}{ Home ownership } \\
\hline $0 \%-71 \%$ & Reference & Reference & Reference & Reference \\
\hline $71.1 \%-80 \%$ & $1.05(0.75-1.48)$ & 0.758 & $0.96(0.65-1.41)$ & 0.822 \\
\hline$>80 \%$ & $1.02(0.77-1.37)$ & 0.871 & $1.00(0.72-1.37)$ & 0.985 \\
\hline \multicolumn{5}{|l|}{ County setting } \\
\hline Large central metro & Reference & Reference & Reference & Reference \\
\hline Large fringe metro & $1.06(0.80-1.41)$ & 0.688 & $1.04(0.76-1.43)$ & 0.806 \\
\hline Small/medium metro & $0.90(0.59-1.38)$ & 0.641 & $0.78(0.49-1.24)$ & 0.301 \\
\hline Insurance status & $1.06(0.70-1.61)$ & 0.780 & $0.92(0.57-1.51)$ & 0.756 \\
\hline
\end{tabular}

Canada retrospectively reported that $44.7 \%$ of 159 middle school, high school, and collegiate student-athletes were returned to school prematurely, which was defined as symptom recurrence upon return to learn. ${ }^{2}$ However, does it mean that a student-athlete was returned to school too early if their symptoms returned, or could the appropriate policy have been followed, only for the student-athlete not to respond as previously thought? Even if we held the first proposed hypothesis - that those with private insurance received appropriate cognitive rest-our explanation would be challenged by the results of a recent observa-

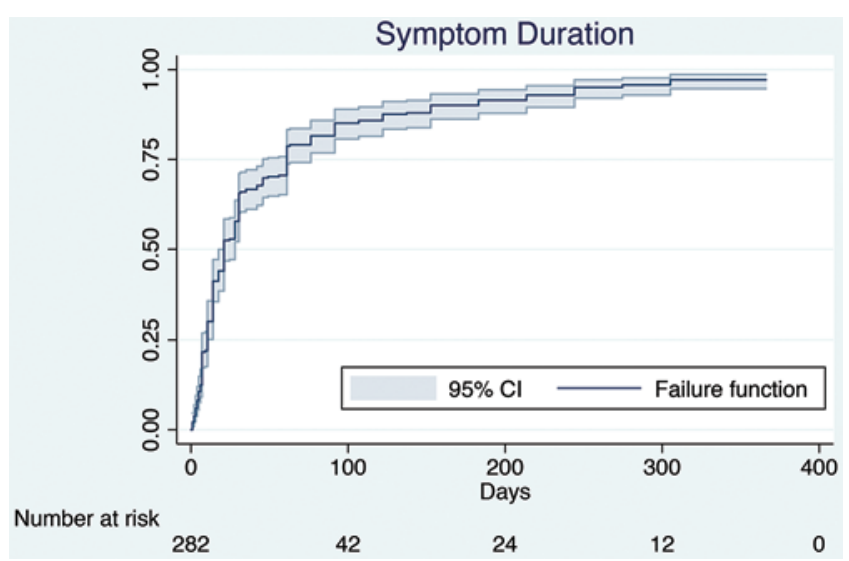

FIG. 2. Graph showing symptom duration. Figure is available in color online only. tional study by Moor et al.., ${ }^{18}$ who measured adherence to postinjury treatment recommendations in 56 concussed adolescent student-athletes. Those who were less adherent to physical rest, mental rest, and school restrictions actually recovered faster than those who followed the prescribed recommendations. Despite speculation and proposed hypotheses, it remains unclear what group of patients receives the optimal post-SRC care. Future works are needed to discern the relationship between SES and how athletes are returned to school. Given the preliminary nature of our study and the surrogate measures used for

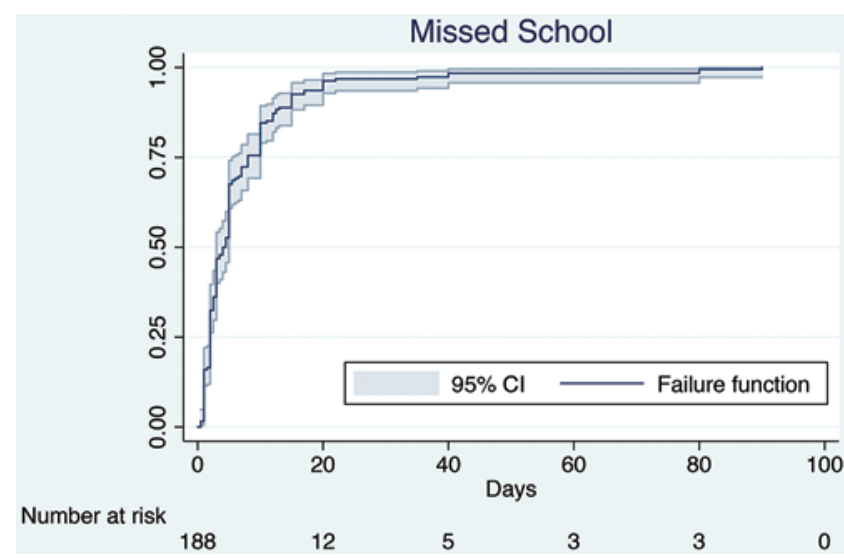

FIG. 3. Graph showing missed school. Figure is available in color online only. 


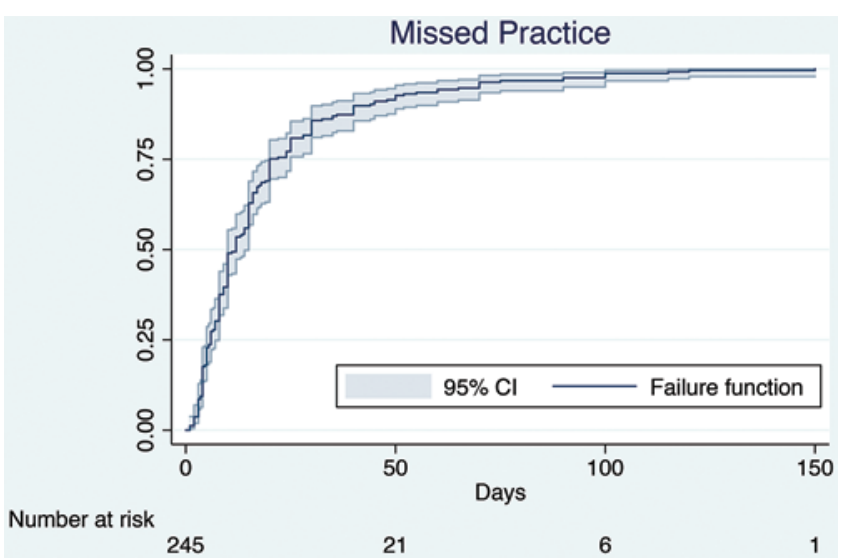

FIG. 4. Graph showing missed practice. Figure is available in color online only.

SES, we offer no concrete recommendations, but rather we hope to spark future research on the relationship of SES to SRC outcomes.

\section{Limitations}

As with any preliminary investigation, there are several study flaws that preclude definitive conclusions. The 2 most important biases concern generalizability and reliability. Although major efforts were made to contact patients and their guardians at multiple time points, we were only able to capture $42.2 \%$ of student-athletes, and due to other exclusion criteria, only $40.3 \%$ were analyzed. Unfortunately, no claims can be made regarding the remaining $59.7 \%$. This immediately calls into question the representativeness of the study cohort. Because contact was made through telephone interviews, we inadvertently selected for patients who were more able and willing to enroll in the study. There may be additional heterogeneity within the remaining population that reflects different trends than the ones presented. We urge future investigators to obtain research data during the concussion provider visit to avoid these limitations in representativeness.

The second study flaw relates to using zip codes as a surrogate for SES. The optimal methodology to collect SES information is through direct patient interview. At the time of our registry design, although we asked many indepth demographic, medical, and sport-specific questions, we failed to delve into the commonly used strategies for assessing SES. Furthermore, no validated questionnaires were used. Although some population-based information can be obtained through zip codes, their use is suboptimal in a study of a highly selected group of patients such as ours. When socioeconomic factors are determined by a thirdhand source such as zip codes, only generic conclusions can be made to spark further study. Recommendations for specific, targeted interventions are prohibited. Although 282 participants is low for a population-based study, in a more narrow SRC cohort, this number is quite reasonable.

Other weaknesses of the study deserve further mention. Student-athletes and their guardians may have been unable to remember specific SRC information months and sometimes years after their injury. However, collateral in-

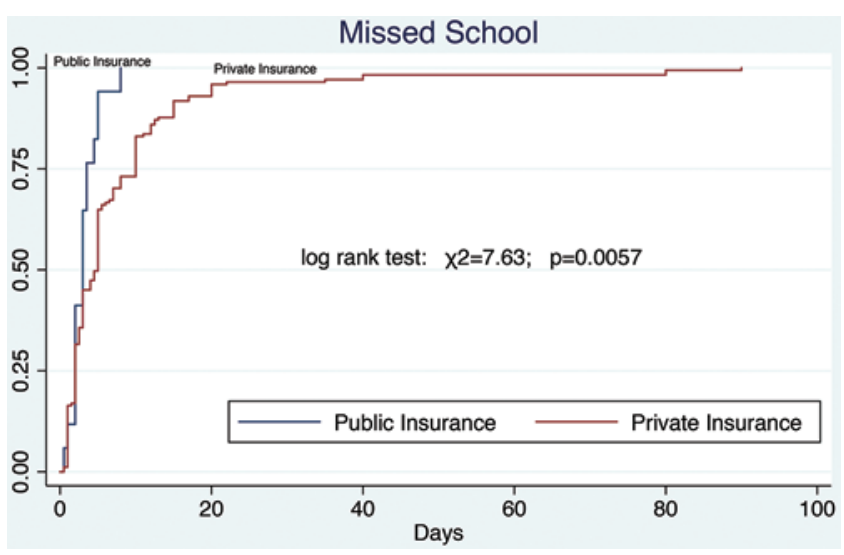

FIG. 5. Graph showing missed school divided by private and public insurance. Figure is available in color online only.

formation was obtained on all patients when available, to counteract recall bias. Our study also represents trends in one region of the country, and sporting activities may not reflect regional trends found elsewhere. In general, this cohort $(85 \%$ white and $90 \%$ with private insurance) reflects a fairly high SES and was obtained from a dedicated SRC clinic at an urban comprehensive medical center. Therefore, it may not reflect population trends in more rural and underserved areas. Last, the 6-part definition of SES used in this study may not have been ideal, and further studies might choose to use other standardized definitions.

\section{Future Research}

Despite the aforementioned limitations, an interesting finding pertaining to time away from school was found, which generates novel hypotheses for future study. The highest utility of this conclusion is not with interpreting the study results outright and disseminating it to coaches, parents, and children. Rather, this finding may represent an important phenomenon that warrants additional investigation with larger, prospective, and multiinstitutional research efforts. If the results are confirmed, this could have important implications for those treating concussed athletes everywhere. Does the quicker return to school among those with public insurance represent a more active rehabilitation process or a premature return to normal routine? The topic of active rehabilitation versus prescribed rest is a major area of interest in the SRC literature, and was the topic of a 2-day, multidisciplinary meeting of national experts in Pittsburgh, Pennsylvania. ${ }^{3}$ Strict brain rest may in fact exacerbate the effect of the inciting injury. The committee strongly recommended against the previously followed "cocoon" therapy. If results can be confirmed that SES leads to a longer duration of absence from school, this may be viewed as too much rest, and a more active approach may be superior.

\section{Conclusions}

The current pilot study sought to evaluate the impact of SES on SRC outcomes. No surrogate SES factors were found to correlate with duration of symptoms or return to sport; however, patients with private insurance took lon- 
ger to return to school than those with public insurance. Given the exploratory nature of our study and novelty of associating socioeconomic factors with SRC outcomes, we urge future investigators to conduct further prospective trials with improved capture rates and reliable assessments of SES.

\section{Acknowledgements}

We thank Rachel Walden and the research team at Eskind Library for their assistance in the literature review.

\section{References}

1. Adler NE, Newman K: Socioeconomic disparities in health: pathways and policies. Health Aff (Millwood) 21:60-76, 2002

2. Carson JD, Lawrence DW, Kraft SA, Garel A, Snow CL, Chatterjee A, et al: Premature return to play and return to learn after a sport-related concussion: physician's chart review. Can Fam Physician 60 (6 e310):e310, e312-e315, 2014

3. Collins MW, Kontos AP, Okonkwo DO, Almquist J, Bailes J, Barisa M, et al: Statements of Agreement from the Targeted Evaluation and Active Management (TEAM) Approaches to Treating Concussion Meeting held in Pittsburgh, October 15-16, 2015. Neurosurgery 79:912-929, 2016

4. Doocy S, Burnham G: Assessment of socio-economic status in the context of food insecurity: implications for field research. World Health Popul 8:32-42, 2006

5. Gessel LM, Fields SK, Collins CL, Dick RW, Comstock RD: Concussions among United States high school and collegiate athletes. J Athl Train 42:495-503, 2007

6. Hart T, Fann JR, Chervoneva I, Juengst SB, Rosenthal JA, Krellman JW, et al: Prevalence, risk factors, and correlates of anxiety at 1 year after moderate to severe traumatic brain injury. Arch Phys Med Rehabil 97:701-707, 2016

7. Hou R, Moss-Morris R, Peveler R, Mogg K, Bradley BP, Belli A: When a minor head injury results in enduring symptoms: a prospective investigation of risk factors for postconcussional syndrome after mild traumatic brain injury. $\mathbf{J}$ Neurol Neurosurg Psychiatry 83:217-223, 2012

8. Ingram DD, Franco SJ: 2013 NCHS Urban-Rural Classification Scheme for Counties. Hyattsville, MD: US Department of Health and Human Services/Centers for Disease Control and Prevention, 2014 (https://www.cdc.gov/nchs/data/ series/sr_02/sr02_166.pdf) [Accessed February 1, 2017]

9. Kasamatsu T, Cleary M, Bennett J, Howard K, McLeod TV: Examining academic support after concussion for the adolescent student-athlete: perspectives of the athletic trainer. J Athl Train 51:153-161, 2016

10. Langlois JA, Rutland-Brown W, Wald MM: The epidemiology and impact of traumatic brain injury: a brief overview. J Head Trauma Rehabil 21:375-378, 2006

11. Liu WM: Expanding our understanding of multiculturalism: developing a social class worldview model, in Pope-Davis DB, Coleman HLK (eds): The Intersection of Race, Class, and Gender in Multicultural Counseling. Thousand Oaks, CA: Sage, 2001

12. Marcin JP, Schembri MS, He J, Romano PS: A populationbased analysis of socioeconomic status and insurance status and their relationship with pediatric trauma hospitalization and mortality rates. Am J Public Health 93:461-466, 2003

13. Max JE, Schachar RJ, Levin HS, Ewing-Cobbs L, Chapman SB, Dennis M, et al: Predictors of attention-deficit/ hyperactivity disorder within 6 months after pediatric traumatic brain injury. J Am Acad Child Adolesc Psychiatry 44:1032-1040, 2005

14. McCrea M, Guskiewicz K, Randolph C, Barr WB, Ham- meke TA, Marshall SW, et al: Incidence, clinical course, and predictors of prolonged recovery time following sport-related concussion in high school and college athletes. J Int Neuropsychol Soc 19:22-33, 2013

15. McCrory P, Meeuwisse W, Aubry M, Cantu B, Dvořák J, Echemendia R, et al: Consensus statement on Concussion in Sport-The 4th International Conference on Concussion in Sport held in Zurich, November 2012. Phys Ther Sport 14:e1-e13, 2013

16. McNally KA, Bangert B, Dietrich A, Nuss K, Rusin J, Wright $\mathrm{M}$, et al: Injury versus noninjury factors as predictors of postconcussive symptoms following mild traumatic brain injury in children. Neuropsychology 27:1-12, 2013

17. Meehan WP III, Mannix RC, Stracciolini A, Elbin RJ, Collins MW: Symptom severity predicts prolonged recovery after sport-related concussion, but age and amnesia do not. J Pediatr 163:721-725, 2013

18. Moor HM, Eisenhauer RC, Killian KD, Proudfoot N, Henriques AA, Congeni JA, et al: The relationship between adherence behaviors and recovery time in adolescents after a sports-related concussion: an observational study. Int J Sports Phys Ther 10:225-233, 2015

19. Morgan CD, Zuckerman SL, Lee YM, King L, Beaird S, Sills AK, et al: Predictors of postconcussion syndrome after sports-related concussion in young athletes: a matched casecontrol study. J Neurosurg Pediatr 15:589-598, 2015

20. Oakes JM, Rossi PH: The measurement of SES in health research: current practice and steps toward a new approach. Soc Sci Med 56:769-784, 2003

21. Olsson KA, Lloyd OT, Lebrocque RM, McKinlay L, Anderson VA, Kenardy JA: Predictors of child post-concussion symptoms at 6 and 18 months following mild traumatic brain injury. Brain Inj 27:145-157, 2013

22. Penson DF, Stoddard ML, Pasta DJ, Lubeck DP, Flanders SC, Litwin MS: The association between socioeconomic status, health insurance coverage, and quality of life in men with prostate cancer. J Clin Epidemiol 54:350-358, 2001

23. Rabinowitz AR, Li X, McCauley SR, Wilde EA, Barnes A, Hanten G, et al: Prevalence and Predictors of Poor Recovery from Mild Traumatic Brain Injury. J Neurotrauma 32:14881496, 2015

24. Rassovsky Y, Levi Y, Agranov E, Sela-Kaufman M, Sverdlik A, Vakil E: Predicting long-term outcome following traumatic brain injury (TBI). J Clin Exp Neuropsychol 37:354-366, 2015

25. Schwartz L, Taylor HG, Drotar D, Yeates KO, Wade SL, Stancin T: Long-term behavior problems following pediatric traumatic brain injury: prevalence, predictors, and correlates. J Pediatr Psychol 28:251-263, 2003

26. Taylor HG, Yeates KO, Wade SL, Drotar D, Stancin T, Minich N: A prospective study of short- and long-term outcomes after traumatic brain injury in children: behavior and achievement. Neuropsychology 16:15-27, 2002

27. Thomas DG, Apps JN, Hoffmann RG, McCrea M, Hammeke $\mathrm{T}$ : Benefits of strict rest after acute concussion: a randomized controlled trial. Pediatrics 135:213-223, 2015

28. Upchurch C, Morgan CD, Umfress A, Yang G, Riederer MF: Discharge instructions for youth sports-related concussions in the emergency department, 2004 to 2012. Clin J Sport Med 25:297-299, 2015

29. West TA, Marion DW: Current recommendations for the diagnosis and treatment of concussion in sport: a comparison of three new guidelines. J Neurotrauma 31:159-168, 2014

30. Wijtzes AI, Jansen W, Bouthoorn SH, Pot N, Hofman A, Jaddoe VW, et al: Social inequalities in young children's sports participation and outdoor play. Int J Behav Nutr Phys Act 11:155, 2014

31. Winkleby MA, Jatulis DE, Frank E, Fortmann SP: Socioeconomic status and health: how education, income, and occupa- 
tion contribute to risk factors for cardiovascular disease. Am J Public Health 82:816-820, 1992

32. Yeates KO, Swift E, Taylor HG, Wade SL, Drotar D, Stancin $\mathrm{T}$, et al: Short- and long-term social outcomes following pediatric traumatic brain injury. J Int Neuropsychol Soc 10:412-426, 2004

33. Zuckerman SL, Yengo-Kahn AM, Buckley TA, Solomon GS, Sills AK, Kerr ZY: Predictors of postconcussion syndrome in collegiate student-athletes. Neurosurg Focus 40(4):E13, 2016

\section{Disclosures}

Dr. Solomon receives consulting fees from the Tennessee Titans (National Football League [NFL]), the Nashville Predators

(National Hockey League), and the athletic departments for several universities (University of Tennessee, Tennessee Tech-fees paid to institution). In addition he is a member of the ImPACT Scientific Advisory Board and receives reimbursement for expenses to board meetings. Dr. Sills is a consulting physician to the Nashville Predators (uncompensated) and also serves as an unaffiliated neurotrauma consultant for the NFL. Dr. Bonfield serves as an unaffiliated neurotrauma consultant for the NFL. Dr. Zuckerman, Mr. Totten, Mr. Rubel, Mr. Kuhn, Mr. Zalneraitis, and Dr. Yengo-Kahn report no conflicts.

\section{Author Contributions}

Conception and design: Zuckerman, Bonfield, Solomon. Acquisition of data: Zuckerman, Totten, Rubel. Analysis and interpretation of data: Zuckerman, Zalneraitis, Totten, Rubel, Yengo-Kahn. Drafting the article: Zuckerman, Zalneraitis, Totten, Kuhn, Yengo-Kahn. Critically revising the article: Zuckerman, Kuhn, Yengo-Kahn, Solomon. Reviewed submitted version of manuscript: Zuckerman, Zalneraitis, Kuhn, Bonfield, Sills, Solomon. Approved the final version of the manuscript on behalf of all authors: Zuckerman. Statistical analysis: Zuckerman. Administrative/technical/material support: Bonfield, Sills, Solomon. Study supervision: Bonfield, Sills, Solomon.

\section{Supplemental Information}

\section{Previous Presentations}

This project was presented in abstract and poster form on October 27, 2016, at the 5th International Consensus Conference on Concussion in Sport in Berlin, Germany.

\section{Correspondence}

Scott L. Zuckerman, Department of Neurological Surgery, Vanderbilt University School of Medicine, Medical Center North T-4224, Nashville, TN 37212. email: scott.zuckerman@vanderbilt.edu. 